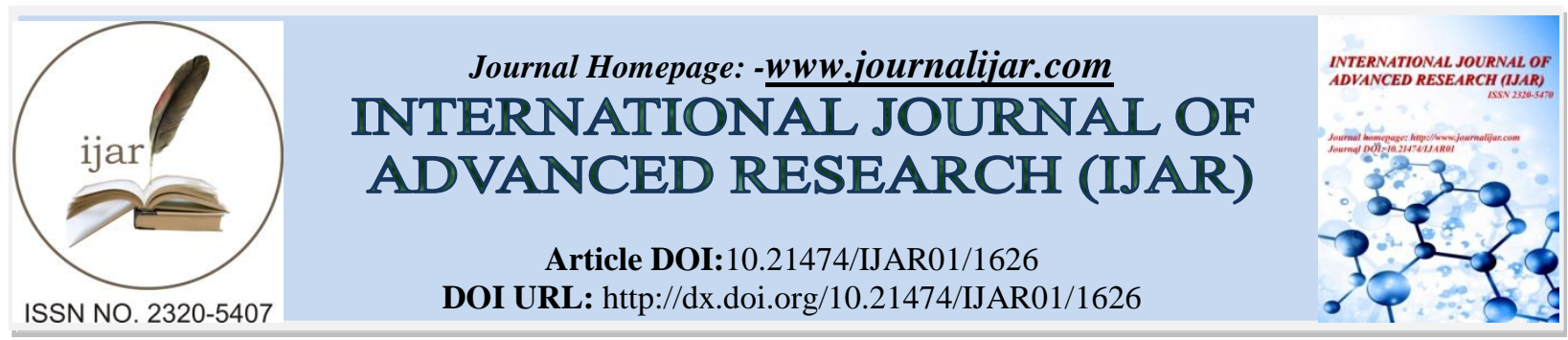

RESEARCH ARTICLE

\title{
New species of genus Sphincterostoma Yamaguti, 1937 reported from Bagridae (Bleeker, 1858) catfish Rita rita (Siluriformes: Bagridae) of River Indus at District Jamshoro, Sindh, Pakistan.
}

\section{Hira Soofi ${ }^{1}$, Nadir Ali Birmani ${ }^{1}$ and Arifa Bhutto ${ }^{2}$.}

1. Department of Zoology, University of Sindh, Jamshoro, Sindh, Pakistan.

2. Department of Information and Communication Technology, University of Sindh, Jamshoro, Sindh, Pakistan.

\section{Manuscript Info}

Manuscript History

Received: 12 July 2016

Final Accepted: 19 August 2016

Published: September 2016

Key words:-

Sphincterostoma alirazi n. sp., Bagridae, Catfish Rita rita.

\section{Abstract}

During current study on helminth parasites of Bagridae Bleeker, 1858 freshwater catfishes Rita rita (Siluriformes: Bagridae) collected from River Indus at District Jamshoro, Sindh, Pakistan. During helminths examination 5 trematodes were collected from intestine of Rita rita Hamilton, 1822. Specimens were processed with stander method. The differential characters of new species are body shape and size, greatest width at pre-equatorial region of body, suckers shape and position, sphincter shape and position, testes shape and position, ovary diamond or triangular in shape, seminal vesicle shape and positions, uterus in the form of thick coils fill with large square shape eggs, vitelline follicles thick in patches form, excretory vesicle heart shape, eggs shape and size, hence new species Sphincterostoma alirazi of genus Sphincterostoma Yamaguti, 1937 completely differs from previously known species and identified as such.

Copy Right, IJAR, 2016,. All rights reserved.

\section{Introduction:-}

More than 186 freshwater fish species described from freshwater bodies of Pakistan. Annually from Pakistan large quantities of commercially valuable fishes caught from rivers. The inland commercially important innate fish fauna and in which the economically important species are: Labeo rohita, Gibelion catla, Cirrhinus mrigala, Cirrhinus reba, Channa straita, Channa marulius, Sperata sarwari, Wallago attu, Rita rita, Bagarius bagarius, Tenualosa ilisha, Notopterus notopterus, Tor macrolepis and Clupisoma naziri (Peter, 1999). The origin of catfish family Bagridae from Africa and Asia, Japan to Borneo (Nelson, 2006). Fishes of family Bagridae generally known as naked catfishes or bagrid catfishes. For the source of food large Bagrid fishes are use. The catfishes of Bagridae carnivorous (Nawaz et al., 1994). These fish can act as an intermediate or a final host for many helminth parasites, due to their feeding habit. Several aspects of helminth parasites of Bagridae air-breathing catfishes described by number of researchers (Reddy et al., 2011). Work on parasites of freshwater catfishes are so diverse but reports on the catfishes of Pakistan are limited to those of (Ahmad et al., 2014; Ayaz et al., 2013; Khanum et al., 2008; Shakir and Khan, 2006; Soofi et al., 2015 and 2016). Whereas, no attempt has been made to undertake research on the helminth parasites of catfishes in Pakistan especially in anticipated area of study. It was therefore proposed that the studies be carried out for the presence of helminth fauna in catfishes of river Indus at Jamshoro district, Sindh, Pakistan. 


\section{Materials and Method:-}

The host Bagridae catfishes Rita rita collected from River Indus at District Jamshoro, Sindh, Pakistan. 67 host were dissected and 5 trematodes were collected from intestine of Rita rita fishes. Specimens were processed fixed under slight cover glass pressure, stained with Borax carmine, dehydrated in a graded series of ethanol solutions, cleared in clove oil and xylol, mounted in Canada balsam. Illustrations were made with aid of camera-lucida. All measurements are given in millimeters $(\mathrm{mm})$. Specimens were identified and compared with the literature. Method described by (Garcia and Ash, 1979; Schmidt, 1988) were followed. Specimens were deposit in Department of Zoology University of Sindh, Jamshoro, Pakistan.

\section{Result:-}

Family Lepocreadiidae (Odhner, 1905) Nicoll, 1935

Genus Sphincterostoma Yamaguti, 1937

Sphincterostoma alirazi n. sp. (Fig. 1 and 2)

\subsection{Taxonomic Summary:-}

Host: Rita rita

Location: Intestine

Locality: River Indus at Jamshoro, Sindh, Pakistan

Number of specimen: 5 from 67 hosts

Type specimens: specimens were deposit in Department of Zoology, University of Sindh, Jamshoro, Pakistan. Etymology: The name of new species refers to the honored of author's brother name Soofi Ali Raza.

\subsection{Description:-}

Body of warm broad, thick, elongate measures 2.37-2.12 X 0.69-0.87 broad fore body and narrow hind body with rounded ends. Greatest width at pre-equatorial region of body. Oral sucker strongly muscular, rounded to wheel shape, terminal, larger then ventral sucker measures 3.7-3.9 X 0.3-0.7. Sphincter of oral sucker sub-terminal. Pharynx well developed, spherical in shape, muscular measures 0.19-0.21 X 0.22-0.23. Caeca narrow extended from posterior end of oral sucker to posterior extremity of body, but overlapped at middle of body. Ventral sucker rounded to spherical, muscular, smaller then oral sucker, at left lateral side of oral sucker measures 0.3-0.6 X 0.29. Two testes equatorial, anterior testis small oval in shape and much overlapped by vitelline follicles measures 0.22 $0.43 \times 0.16-0.17$, posterior testis large, oval to elongate in shape, little overlapped by vitelline follicles measures 0.3 $\mathrm{X}$ 0.17-0.19. Ovary diamond shape, triangular, pre-testicular, highly overlapped by vitelline follicles measures $0.34-$ 0.37 X 0.26-0.32. Seminal vesicles long at lateral side of ventral sucker. Genital pore median in front of ventral sucker. Uterus in the form of thick coils fill with large square shape eggs, extended from posterior end of ventral sucker to anterior end of anterior testis. Vitelline follicles thick in patches form, extended from ventral sucker to posterior extremity of body, anteriorly overlapped by uterus. Excretory vesicle heart shape, form cloacal aperture, sub-terminal. Eggs square shape, large, some overlapped each other, double lined measures 0.14-0.22 X 0.07-0.17.

\section{Discussion:-}

Genus Sphincterostoma (Yamaguti, 1937) parasites of marine and freshwater fishes found in intestine. Type species Sphincterostoma branchiostegi (Yamaguti, 1937) collected from Branchiostegus japonicus of Japan. The new species Sphincterostoma alirazi compare with previously reported species of genus showing following difference.

S. branchiostegi (Yamaguti, 1937) collected from intestine of Branchiostegus japonicus of Japan differs from present species in having $4.4 \times 0.4$ in size; oral sucker sub-terminal at the center of anterior extremity of body; oral sphincter terminal; pharynx spherical in shape; caeca well developed, wider, V- shape posteriorly; ventral sucker at post-bifurcated level; seminal vesicle retort in shape, postero-dorsal to acetabulum; ovary rounded, sub-median between right caecum and seminal vesicle; testes two oval to rounded, separated from each other by space; uterus with few coils, eggs oval in shape; vitelline follicles extending between level of caecal bifurcation and posterior extremity of body; excretory vesicle elongate, tubular.

S. ompokii (Zaidi and khan, 1977) collected from intestine of Ompok bimaculatus of Pakistan differs from present species in having $3.10 \mathrm{X} 0.84$ in size; oral sucker less muscular; prepharynx present; pharynx at posterior end of ventral sucker; caeca join at posterior extremity from cloacal aperture; ventral sucker situated at anterior end and central in position, posteriorly overlapped by pharynx; testes oval in shape, separated by vitellaria; seminal vesicle 
postero-dorsal to ventral sucker; ovary behind the ventral sucker; vitelline follicles extended from posterior margin of oral sucker to posterior extremity of body; eggs oval in shape; excretory vesicle tubular.

The new species show diagnostic differential characters from all previously recorded species of genus such as body shape and size, greatest width at pre-equatorial region of body, oral sucker shape rounded to wheel shape and size, sphincter position, pharynx spherical in shape, ventral sucker shape rounded to spherical size and position, testes shape and size, ovary diamond or triangular shape and size, uterus in the form of thick coils fill with large square shape eggs, vitelline follicles thick in patches form, excretory vesicle heart shape, eggs square shape, hence purposed as Sphincterostoma alirazi n. sp.
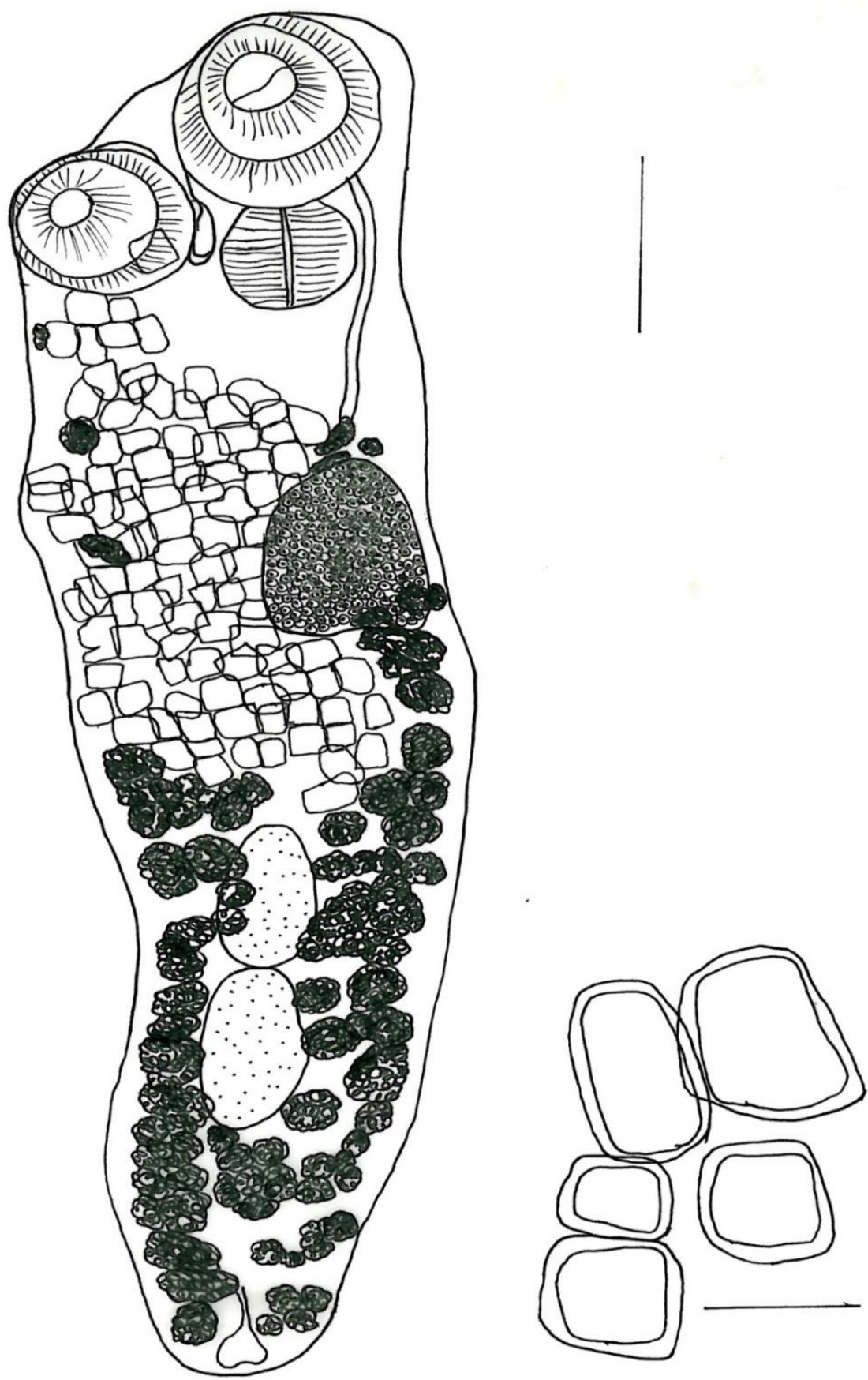

Fig. 1. Sphincterostoma alirazi n. sp. Diagram showing all morphological characters of entire specimen and eggs with scale bar 0.3 and $0.1 \mathrm{~mm}$. 

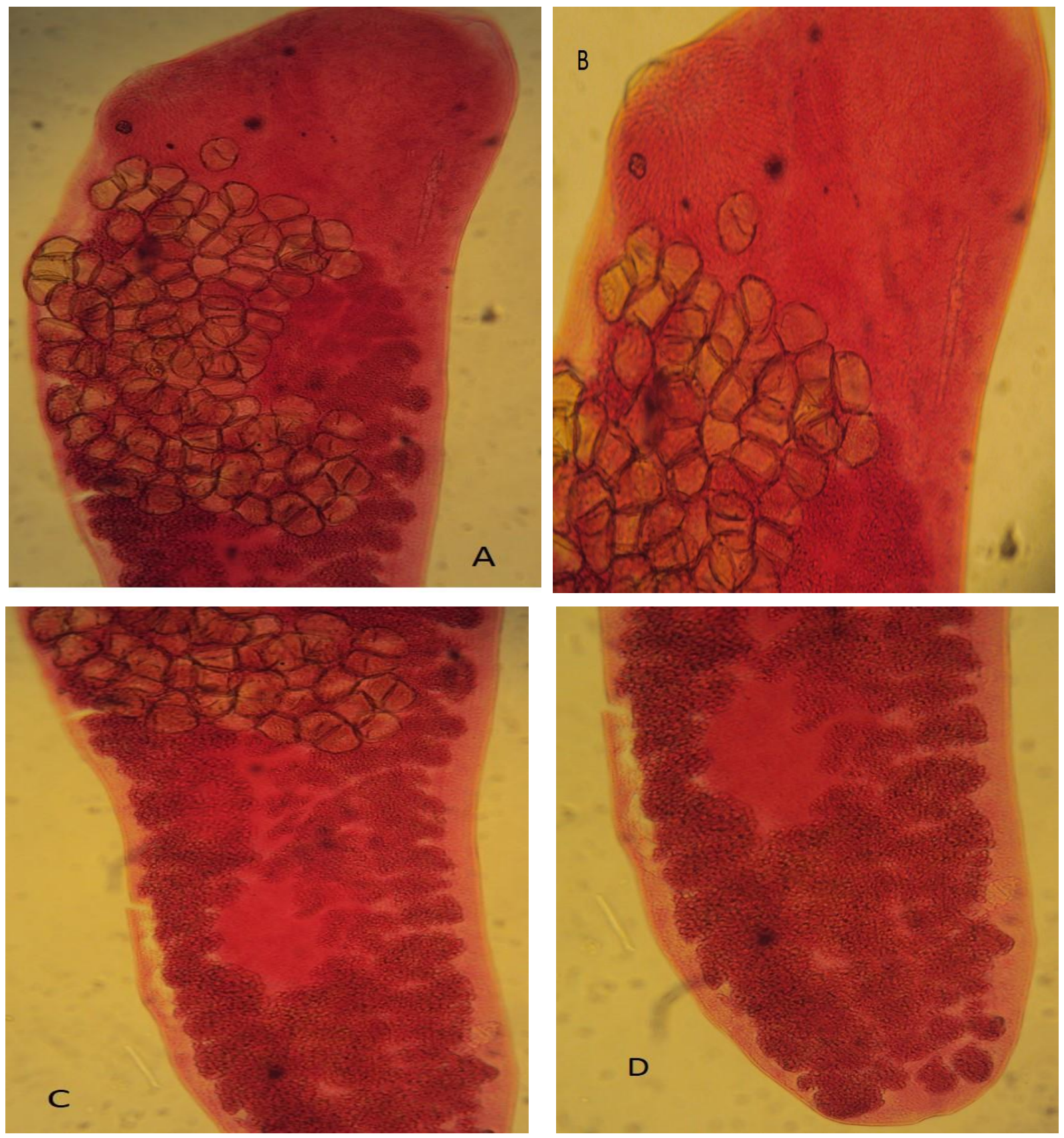

Fig. 2. Sphincterostoma alirazi n. sp. Photographs of worm A and B anterior end, C. middle portion and D. posterior end. 


\section{References:-}

1. Ahmad, N., Ayaz, S., Shams, S. and Karimullah. 2014. Prevalence and Morphology of Helminth Parasites of Fish from River Swat, Khyber Pakhtunkhwa. Pakistan Journal of Agriculture and Research 27(2): 142-148.

2. Ayaz, S., Khan, M.A., Rehman, I.U., Anwar, M., Saeed, S. and Zarin, S. 2013. Prevalence of Endoparasites in Fresh Water Fishes in River Punjkorha, Khyber Pukhtunkhwa Pakistan. International Journal of Biology, Pharmacy and Allied Sciences 2(1): 111-115.

3. Bilqees, F.M. 1986. Digenetic trematode of freshwater fishes of Pakistan. Proceeding of Parasitology 2: 74-108.

4. Garcia L.A., Ash L.R. 1979. Diagnostic Parasitology Clinical laboratory manual. The CV Mosby Company. 11830 West line Industrial Drive, St. Louis, Missouri 63141.

5. Jones, A., Bray, R.A., Gibson, D.I. 2005. Keys to the Trematoda Volume -2. The Natural History Museum, London, UK, 47: 120-137.

6. Khanum, H., Ferdows, J., Farhana, R. 2008. Community of Helminth Parasites in Rita rita (Hamilton Buchanun) Journal of Bioscinces 16:133-135.

7. Nelson, J.S. 2006. Fishes of the World. John Wiley \&Sons, Inc., ISBN 0-471. p25031.

8. Nawaz, H Sharif, M.H, Mirza, M.R. 1994. Food of the singhari, Aorichthys aor sarwari (Pisces: Bagridae). Biologia Lahore 40 (1-2): 103-107.

9. Peter, T. 1999. Coldwater fish and fisheries in Pakistan. FAO Fisheries, Rome. Technical Paper 385:122-137.

10. Reddy, Y., Wankhede, H., Dhole, J., Anand, S. 2011. A new Proteocephalidean tapeworm, Gangesia (Gangesia) bendsurensis n. sp. from fresh water catfish, Wallago attuat Beed district (M.S.), India. International Multidisciplinary Research Journal 1(8): 31-34.

11. Shakir, H.A., Khan, A.M. 2006. The Prevalence of Cestode Infection in a freshwater catfish, Sperata Sarwari, Dept. Zool., P.U., Lahore, Pakistan. Punjab University Journal of Zoology 21(1-2): 41-47.

12. Schmidt G.D. 1988. Essentials of Parasitology 4th Edition. W.M.C. Brown Publishers 2460 Keper Boulevard, Dubuque, IA 52001. p294.

13. Soofi, H., Birmani, N.A., Dharejo, A.M., Abbasi, A.B. 2015. First record of genus Thaparotrema Gupta, 1955 (Trematoda: Ophisthorchiidae) in Pakistan. Journal of Entomology and Zoology Studies 3(6): 232-234.

14. Soofi, H., Birmani, N.A., Dharejo, A.M. 2016. Dendrorchis ritata n. sp. (Trematoda: Gorgoderidae) from catfish Rita Rita (Siluriformes: Bagridae) of Sindh, Pakistan. International Journal of Fauna and Biology Studies 3(3): 17-19.

15. Yamaguti, S. 1971. Synopsis of digenetic trematodes of vertebrates Volume-1 Keigaku publishing Co. Tokyo, Japan. P. 165-166.

16. Yamaguti, S. 1971. Synopsis of digenetic trematodes of vertebrates Volume-2. Keigaku publishing Co. Tokyo, Japan. P. 399. 